\title{
Epilepsy and its Association with Depression
}

\author{
Sukaina Rizvi ${ }^{1}$, Hina Saeed ${ }^{2}$, Danish Kherani ${ }^{3}$, Talha Naser Jilani ${ }^{4}$ and Kamil Dar ${ }^{5}$ \\ ${ }^{1}$ Newbridge Medical Center, USA \\ ${ }^{2}$ Baqai Medical University, Pakistan \\ ${ }^{3}$ Ziauddin University, Pakistan \\ ${ }^{4}$ Ziauddin University, Pakistan \\ ${ }^{5}$ Cambridge Health Alliance, USA
}

Submission: July 31, 2018; Published: August 17, 2018

*Corresponding author: Sukaina Rizvi, Newbridge Medical Center, USA, Email: sukainarizvi812@gmail.com

Abstract

Depressive disorder is a frequent comorbid psychiatric condition in patients with epilepsy. It is more common in patients with temporal lobe epilepsy and frontal lobe seizures. Research has revealed a strong correlation between these two conditions. The early recognition of depressive symptoms in an epileptic patient is a predictor to improve quality of life. Besides treating epilepsy, antiepileptics have a role in treating nonepileptic conditions like mood disorders and pain syndromes. However, it is to be considered that certain antiepileptics decrease seizure threshold and increase seizure frequency.

\section{Introduction}

Over the years, a significant amount of research has been conducted showing relationship between epilepsy and depression. Epilepsy and depression are common conditions and often they occur together. Approximately, 40-60\% people with epilepsy are affected with depressive symptoms [1]. This is a review article highlighting a strong association between two entities. The main idea behind this review article is to encourage practitioners to keep a close eye on symptoms of depression in people with epilepsy and to treat them accordingly which can impact positively on their quality of life.

\section{Discussion}

what is epilepsy? It is important to understand epilepsy on individual basis before moving on further. Epilepsy or a "seizure disorder" is a neurological condition affecting people of all ages. It involves a spectrum of various kinds of seizures, each presenting in a unique way in person to person. The two terms Epilepsy and seizure are used interchangeably; however, these are different in a context of frequency of occurrence as seizure is a single occurrence and epilepsy is two or more unprovoked seizures. According to Epilepsy foundation there are about 3.4 million people in United states who have epilepsy and there are 150,000 of new cases of epilepsy in the United States each year. It is also evident from a systemic review and meta-analysis research by A. K Ngugi, et al that median incidence of epilepsy as almost twice as high in low income countries than of high income countries [2]. The cause of epilepsy could be familial or could be secondary to stroke, brain infection, traumatic brain injury or idiopathic. Diagnosis requires a multidisciplinary approach including clinical presentation along with EEG, CT scan head, MRI, Neuropsychological testing, blood work. There are some seizures which present with normal finding on EEG. These are called pseudo-seizures and require a detail evaluation by a psychiatrist.

Epilepsy tend to impact a person on physical and psychological grounds as the occurrence of seizure is often uncertain. This could lead to an increase risk of mood disorders, physical trauma, cognitive issues, behavioral disturbances, depression, hospitalizations and mortality [3]. It is evident from a survey in UK that people with epilepsy tend to suffer from anxiety and sleep disorders more than the people without epilepsy [4]. This sleep disturbances and anxiety can significantly affect the quality of life in a negative way predisposing a person to develop depression.

As the focus of medicine has transitioned to research, we are now able to uncover that depression and epilepsy often coexist together. It is approximated that life time prevalence of depression in correlation with epilepsy is about 55\% [5]. The exact cause of this association is still debatable as various mechanisms explain this link. People with depression have sleep deprivation which can decrease seizure threshold and increase 
seizure frequency. Preictal psychiatric symptoms usually consists of a constellation of symptoms preceding seizure and can last from minutes to days including prodromal symptom of depressed mood and irritability which is relieved after the onset of seizure or in some cases after few days of seizure activity [6]. Inter Ictal depression or dysphoria consist of brief episodes of crying spells, feeling of worthlessness, anhedonia, helplessness, hopelessness which usually last less than 30sec. In addition, inter ictal depression is also manifested by agitation, psychotic disturbances and impulse control issues which can ultimately predispose to increased suicidal tendencies [5,7]. It is important to recognize all these phases as their prompt recognition and their immediate treatment can lead to prevention of a seizure activity and would also improve quality of life.

It is stated that Depression affects some parts of limbic system of brain which includes amygdala which is a center for emotional/stress responses and hippocampus which has a role in cognition. This results in reduced hippocampal volume and functional or physical alteration of amygdala. Research publication have demonstrated increased risk of depression in patients with temporal epilepsy [5].

This is supported by the temporal lobe epilepsy refractory to antiepileptic medications that could lead to hippocampal sclerosis [8]. Studies have shown some correlation showing that people who have hippocampal sclerosis had a history of febrile convulsant seizure in childhood. Also, there is a study on infants with complex febrile seizures validating that sometimes complex prolonged febrile seizures can lead to acute hippocampal injury which later evolves to hippocampal atrophy [9]. This phenomenon could also explain an association between epilepsy and depressive symptoms secondary to reduced hippocampal volume.

Antiepileptics also have a significant role in various psychiatric disorders where they are primarily used for mood stabilization and for treating anxiety. However, effects of antiepileptics in terms of their therapeutic benefits and side effect profile varies from person to person. It is important to consider that studies performed on one group of people on AEDs should not be implied to another group. This is even more of significance in patients with epilepsy where there is a considerable variation in response to these drugs based on different reactions. Research has shown that people with epilepsy on antiepileptics are more predisposed to increased risk of depression as compared to the other populations [10]. According to Siddhartha, certain antiepileptics are notorious for this behavior which includes levetiracetam, ethosuximide, phenytoin, topiramate etc., which may precipitate underlying depression or anxiety. However, it is interesting to note that some AEDs like lamotrigine have beneficial effects of antidepressants $[10,11]$. It is stated in publications that each of AEDs act through unique mechanisms which alters the electrochemical gradient resulting in positive or negative behavioral changes. These mechanisms include GABAergic modulation either through stimulating chloride channels or inhibiting GABA uptake and inhibition of voltage gated sodium channels [12]. Landolt hypothesis of forced normalization should also be taken into consideration regarding behavioral manifestation of AEDs which states possibility of depressive symptoms after diminution of epilepsy either through surgery or use of AEDs [5].

There is evidence suggesting that tricyclic antidepressants and MAOI have a dose- dependent potential to decrease seizure threshold. Bupropion has also shown to decrease seizure threshold at all doses. Now there are cases reported in which Bupropion has led to seizure activity even at its extended release formulation. Alternatively, second generation antidepressants SSRI like sertraline, paroxetine, escitalopram does not lower seizure threshold and can be safely used for treating depression in epileptic patient $[13,14]$. There could also be a strong connection among depression, epilepsy and suicide as a people with MDD harm themselves by over ingesting antidepressants which could be lethal causing seizures or on the other hand, a people with epilepsy can become depressed over time with their illness and try to commit suicide.

\section{Conclusion}

In the light of above review article, it is concluded that epilepsy and depression share a unique bidirectional relationship as depression is a most frequent comorbidity in patients with epilepsy. Given their strong correlation a clinician should use a holistic approach to identify depressive symptoms in epileptic patients. There is also a need to investigate about any history of seizure disorder as there is evidence suggesting hippocampal changes in these patients predisposing to depression in later life. It is imperative for practitioners to obtain a through drug history, monitor their drug levels and to make correct choice of antidepressants if treating epilepsy. This also necessitates a need of collaboration between a neurologist and a psychiatrist to manage these conditions.

\section{References}

1. Grabowska-Grzyb A, Jedrzejczak J, Nagańska E, et al. (2006) Risk factors for depression in patients with epilepsy. Epilepsy Behav 8(2): 411-417.

2. Ngugi AK, Kariuki SM, Bottomley C, Kleinschmidt I, Sander JW, et al. (2011) Incidence of epilepsy: a systematic review and meta-analysis. Neurology 77(10): 1005-1012.

3. Kerr MP (2012) The impact of epilepsy on patient's lives. Acta Neurologica 126(194): 1-9.

4. Jacoby A, Snape D, Lane S, Baker GA (2015) A review article: Selfreported anxiety and sleep problems in people with epilepsy and their association with quality of life. Epilepsy Behav 43: 149-158.

5. Jackson MJ, Turkington D (2005) Depression and anxiety in epilepsy. Journal of Neurology Neurosurgery \& Psychiatry 76(1): 45-47.

6. Mula M (2013) Preictal psychiatric symptoms. Epilepsy and behavior 28(2): 318.

7. Schacther SC (2013) Inter Ictal Depression. Epilepsy and behavior 28(2): 319 . 
8. Briellmann RS, Hopwood MJ, Jackson GD (2007) Major depression in temporal lobe epilepsy with hippocampal sclerosis: clinical and imaging correlates. J Neurol Neurosurg Psychiatry 78(11): 1226-1230.

9. VanLandingham KE, Heinz ER, Cavazos JE, Lewis DV (1998) Magnetic resonance imaging evidence of hippocampal injury after prolonged focal febrile convulsions Ann Neurol 43(4): 413-426.

10. Nadkarni S, Devinsky 0 (2005) Psychotropic Effects of Antiepileptic Drugs 5(5): 176-181.

11. Ettinger AB, Argoff CE (2007) Use of antiepileptic drugs for nonepileptic conditions: psychiatric disorders and chronic pain. Neurotherapeutics 4(1): 75-83.
12. Davies JA (1995) Mechanisms of action of antiepileptic drugs. Seizure 4(4): 267-271.

13. Alper K, Schwartz KA, Kolts RL, Khan A (2007) Seizure incidence in Psychopharmacological clinical trials: an analysis of Food and Drug Administration summary basis of approval reports. Biol Psychiatry 62(4): 345-354.

14. Rissmiller DJ, Campo T (2007) Extended-Release Bupropion- Induced Grand Mal seizures. J Am Osteopath Assoc 107(10): 441-442.

\section{Your next submission with Juniper Publishers will reach you the below assets}

- Quality Editorial service

- Swift Peer Review

- Reprints availability

- E-prints Service

- Manuscript Podcast for convenient understanding

- Global attainment for your research

- Manuscript accessibility in different formats

( Pdf, E-pub, Full Text, Audio)

- Unceasing customer service

Track the below URL for one-step submission https://juniperpublishers.com/online-submission.php 